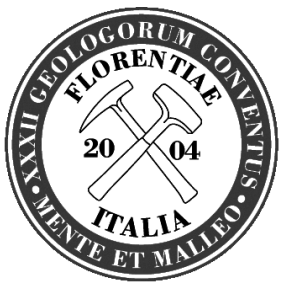

\title{
A strategic vision for the Earth Sciences
}

The following article sets forth the conceptual strategic framework that guided the organization and planning of the recent, highly successful 32nd International Geological Congress, held in Florence, Italy, August 20-28, 2004. This vision of the desired future state of the Earth sciences is presented here in order to extend significantly its distribution beyond the 7000+ Congress participants. Earth scientists around the world are encouraged to consider, digest, and discuss its observations, conclusions, and recommendations to improve the relevance and sharpen the focus of current and future activities in the Earth sciences. [Originally published in the daily newspaper of the Congress, "32nd IGC INFORMS," No. 9, August 28, 2004, and distributed to Congress participants. Available also on the IUGS website.]

1 Dipartimento di Scienze della Terra e Geoambientali, Universita' di Bologna, Italia. E-mail: cavazza@ geomin.unibo.it 2 Dipartimento di Mineralogia e Petrologia, Universita' di Padova, Italia. E-mail: francesco.sassi@ pop.unidp.it

\section{Rationale}

Within and outside the Earth sciences community there is a need to redefine the position of the geosciences in the face of changing societal needs. To tackle challenges and capitalize on the opportunities presented by internal and external change, the international geological community must react quickly and develop a blueprint for the future. A renewed, firm commitment to scientific research and education by all countries, based on a raised level of public understanding and awareness of scientific and technological issues, will be a necessary prerequisite for achieving further human and social development in the future. This is the conceptual framework in which the 32nd IGC was planned and organized.

This brief document, produced by the Organizing Committee of the 32nd International Geological Congress, identifies a vision of the desired future state of the Earth sciences. It does not suggest specific measures to be adopted; instead its purpose is to offer a vision and broad guidelines to Earth sciences officials, researchers, and educators, and natural-resources managers to increase and sharpen the focus of current and future activities. It also provides a common platform for the relations with the communications media.

The vision and scope of this document are developed in relation to four key issues for the Earth sciences at large: (i) new nearfuture opportunities, (ii) improvement of governmental and public perception, also through education and outreach, (iii) fundamental research as an essential generator of new ideas and technological applications, (iv) improved international scientific and technological cooperation as essential for tackling global issues.

Being the most diverse and internationally attended geosciences meeting in the world, the IGC is ideally positioned to provide a periodic benchmark of the state of the geosciences. It is proposed that this Strategic Vision should be revised on the occasion of the future IGCs.

\section{Perspectives}

\section{New opportunities for the Earth sciences}

The geosciences community has played a pivotal role in shaping the world as we know it today by identifying the energy means necessary for the economic and societal development of the last two centuries. This is continuing, yet emphasis has recently shifted toward the application of geological knowledge to environmental issues such as natural hazards, climate change, water management, waste disposal, development planning, and land management. In addition, Earth system science is growing as a new paradigm, explaining the interactions between hydrosphere (including the cryosphere), atmosphere, biosphere and geosphere. The Earth sciences community is currently facing one of the biggest opportunities in its history, as research on the Earth sciences is now needed more than ever. For example, geologic research has shown that Earth's climate can change greatly over short time periods. If society is prepared, it may be able to respond successfully. The faster all geological, Earth, and planetary sciences will react to develop a consistent theoretical background able to predict and manage how to tackle the global challenges, the better we will have contributed to the new societal needs.

Geological knowledge is a prerequisite for land and water management. It is the duty of geological surveys, environmental protection agencies, private companies, geological engineering firms, and academic researchers to provide reliable, objective, and timely geological information and knowledge to central and local governments and the private sector in support of sustainable management of our environment and its infrastructural development as envisaged by government policy. All these elements of the Earth sciences global community have reacted to the increased awareness of the environment and sustainable development by broadening their objectives and lines of action. Vast amounts of geological information are required to develop 
policies and manage resources. This is an accepted notion in relatively few countries and must be implemented worldwide.

\section{Improving government and public perception}

Recent surveys conducted in several major industrial nations indicate a considerable degree of public interest in science as well as appreciation of its contribution toward improving living conditions. However, skepticism as well as outright hostility towards modern science and/or its technological applications have been expressed recently by a wide range of groups and have been widely covered by the communications media. Parts of the public have the feeling that science and technology are becoming too powerful and detached. The decline in public confidence in scientists and technical experts and their respective institutions lies also in their past failures to anticipate and control possible negative consequences of science and technology (e.g., Bhopal, Amoco Cadiz, Chernobyl). It is therefore vital that geoscientists communicate effectively their knowledge to the public and to policymakers in order to increase the understanding of science, to inform policy decisions, and to make new findings accessible to those who might need them. More efficient bridges need to be built between policy, management, and science, as well as between the public and private sectors. Public consensus on the acceptable levels of risk for different kinds of technology must be established. This is the only way of enhancing public confidence in the Earth sciences.

Earth science education is the basis for effective understanding, dissemination and application of geological knowledge in modern technological society. The Earth sciences community must therefore strive for geosciences education to be included in teaching curricula at all levels. This will enable the society (i) to be aware of scientific and technological applications to everyday life, (ii) to make informed judgements about the benefits of science and technology to society, and (iii) to produce a future generation of environmentally aware policymakers. We are moving toward two separate societies, one science literate, of which we are a part, and the other science illiterate. This must be avoided through specific educational and outreach programs, as ignorance fuels misperceptions and irrational reactions. As to geological higher learning, we must make sure that university students are educated in tune with current societal needs.

\section{Implementing research in fundamental geosciences}

The economic context in which science operates has changed and an increasing portion of scientific research is being undertaken by the private sector and by university-industry joint ventures. The commercialisation of scientific knowledge in a policy context which promotes short-term benefits at the cost of long-term projects threatens fundamental research funding and could inhibit international co-operation on projects which require attention on a global scale. Given these limitations on the various sources of funding, science management and science policy will have to invent and implement new mechanisms for generating an investment in fundamental science and the healthy distribution of scientific knowledge. The advancement of science goes hand in hand with its application to human needs, making opposition between fundamental and applied science artificial.

\section{Developing a global geoscientific network}

To address today's global issues such as desertification and sealevel rise, the international Earth sciences community must cooperate at a higher intensity then hitherto practised, especially on global and long-term projects. New cooperation programs, partnerships, networks and strategic alliances need to be created and existing ones need to be strengthened. From this viewpoint, the Internet should be used at full capacity to promote the free and rapid flow of information. This should be implemented not only for short-term, target-driven programs but also for fundamental science, in order to promote a more effective use of financial and human resources. Contrary to common wisdom, the developing countries should participate not only in international applied science programs but also in the research effort in fundamental science, as fundamental science is an important source of scientific and technical expertise which is of prime importance for a country's societal development.

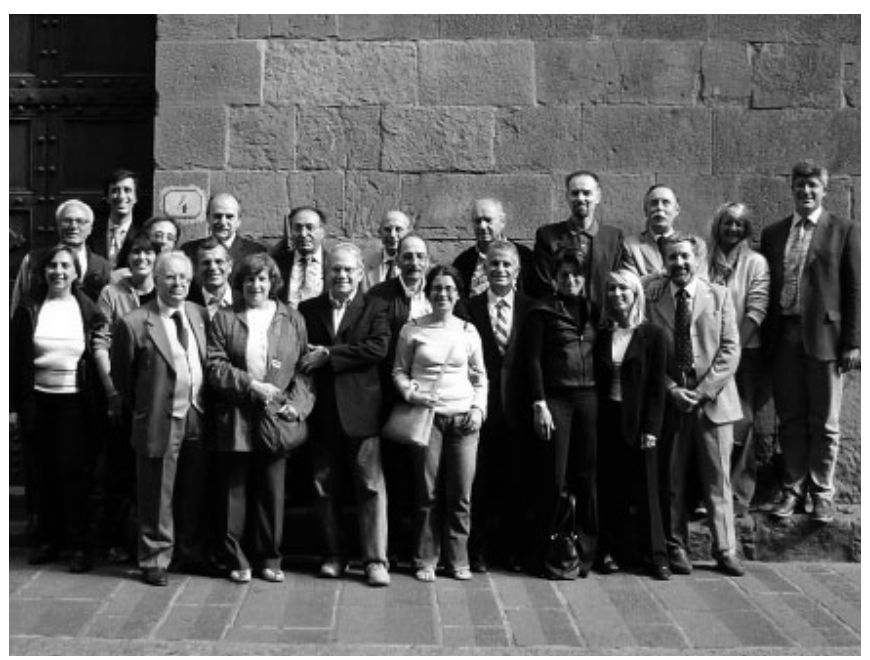

Members of the Organizing Committee of the 32nd International Geological Congress (Florence, 20-28 August 2004).

Front row, left to right: Alba Zappone, Maria Bergomi, Francesco Paolo Sassi, Gian Gaspare Zuffa, Evelina Giobbi, Attilio Boriani (President), Paolo Forti, Francesca Serra, Gian Battista Vai, Paola Meucci, Irene Rischia, Pierluigi Soddu. Back row: Ernesto Abbate (Secretary General), Luca Guerrieri, Tomaso Mazzotti, Alessandro Colombetti, Cesare Roda, Bruno D'Argenio, Antonio Brambati, William Cavazza, Forese Carlo Wezel, Chiara Manetti, Marco Amanti. Other members of the Organizing Committee not shown in the photograph: Pietro Armienti, Riccardo Casale, Cesidio Lippa, Piero Manetti, Claudio Margottini, Paul Mazza, Teodoro Mercuri, Luca Ottenziali, Carlo Alberto Ricci, Leonello Serva, Leonardo Sorelli, and Mario Tozzi. 